\title{
LOS TEXTOS DISPERSOS DE VILLAMEDIANA
}

Reúno y estudio en estas páginas cuantos textos dispersos del Conde de Villamediana he podido encontrar en impresos de los siglos xvi y XvII ${ }^{1}$. Al agruparlos me guiaba, en principio, un interés meramente bibliográfico y de editor. Leídos una sola vez tenían, para la edición de las obras completas de Tassis, indudable importancia porque, además de la rareza de la mayoría:

$1 .^{\circ}$ Seis no habían sido incluidos en sus Obras, pasando desapercibidos a los críticos del Conde.

2. Varios eran anteriores a la primera edición, e incluso anteriores a la muerte del autor, $\mathrm{y}$ fueron publicados con su asentimiento.

3. Otros, entre ellos uno de sus poemas largos, La Fénix, presentan variantes de gran importancia. E1 texto de esta fábula -uno de los más errados en las ediciones-- es, en esta impresión suelta, obra de Pellicer, francamente depurado y coincide siempre con las correcciones e internolaciones manuscritas del ejemplar de la edición príncipe que maneio, lo que autoriza las enmiendas que a toda la obra hizo esta mano de 1633 , de forma sistemática, como si prenarase una impresión correcta.

1 Conviene tener presente, antes de iniciar este estudio, los pies de imprenta de las seis ediciones de sus Obras: Zaragoza, Juan de Lanaja y Quartanet, 1629 ; Zaragoza, Juan de Lanaja y Quartanet, 1634; Madrid, María de @uiñones, 1635 ; Madrid, Diego Díaz de la Carrera, 1643; Madrid, Diego Díaz de la Carrera, 1634 (sic, pero 1643 ó 1644) ; Barcelona, Antonio Lacavallería, 1648. Las ediciones de 7aragoza y Barcelona son iguales en el contenido; las de Madrid, además de copiar el texto de las anteriores, en el mismo orden, añaden al final bastantes composiciones. Hago una detallada descripción de ellas, así como la discusión de los varios problemas que presentan, en $E l$ Conde de Villamediana. Bibliografía y contribución al estudio de sus textos, Madrid, C. S. I. C., 1964 (Cuadernos Bibliográficos, 11). En este libro di ya cuenta de los textos que ahora edito y estudio. 
4. Uno de los textos es el famoso soneto Risa del monte, de las aves liras, de tan problemática atribución tanto a Saavedra Fajardo como al Conde. Propongo un nuevo candidato: Esquilache.

Luego, la lectura detenida de estos textos ha ampliado mi interés por ellos y me ha hecho dedicarles a cada uno un estudio, ya que-olvidando la edición- tienen en sí verdadera importancia para el conocimiento de la obra de Villamediana, por muy diversos motivos:

5. Todos ellos, o están fechados o los podemos datar con mucha aproximación, cosa poco frecuente - es una de las graves dificultades que presenta el estudio de su poesía - en la obra del Conde.

6. Dos de las composiciones, dos sonetos, ambos publicados en 1599, están escritas en plena adolescencia, y representall sus primeros intentos serios de poeta. $\mathrm{Y}$ lo que es importante: en las dos hay ya huellas (o al menos coincidencias) de Góngora, quien para entonces casi nada había editado.

7. Uno de los textos es una de las cuatro finicas prosas que de Villamediana conservamos.

8. Otro de ellos, cuatro octavas, que se relaciona con varios sonetos bien conocidos, es una prueba más de que La Gloria de Niquea, como estimó Dámaso Alonso, en contra de Angulo y Pulgar y Alfonso Reyes. es obra suya y no de Góngora.

9. ${ }^{\circ}$ Varios nos perfilan detalles de su vida $y$ aficiones, y nos llevan una vez más a cuestiones gongorinas, como el soneto epitafio a don Rodrigo Calderón.

1599. - Me había llamado siempre la atención que el Conde, nada más empezar el siglo XVII, tuviese fama de poeta en las lejanas tierras de América. Bernardo de Balbuena lo elogia en su Grandeza mexicana, que apareció en México en $1604^{2}$. Los dos sonetos que a continuación copio explican suficientemente esta fama: Villamediana fue poeta desde muy joven $y$ sus dos primeras composiciones editadas, dos sonetos, van al frente de sendos libros de tema indiano, uno de los cuales estaba escrito por un amigo del Obispo de Puerto Rico, Antonio de Saavedra Guzmán, que había elogiado en los preliminares la Grandeza mexicana.

2 Al final del libro vienen unas Excelencias de la poesía. Dentro de ellas, en el folio 135 r., se hace el elogio de algunos escritores contemporáneos del autor, entre los que está el Conde. Los preliminares del libro son de 1603. 
El primer soneto apareció en el libro de Vargas Machuca, Milicia $y$ descripción de las Indias ${ }^{3}, \mathrm{y}$ dice así :

Gloria y honor del Indico Ocidente, prudente cauallero y animoso. en los trances de Marte valeroso, $y$ en los actos de Palas eloquente;

dichoso tú, cuya inuencible frente. ciñe la flor del lauro victorioso, deuido en Corte al escritor famoso, como en campaña al general valiente.

$Y$ más dichoso el español Imperio, pues tu raro valor $y$ braço alcança en arte $y$ gloria militar tan diestro:

que es fuerça en el Antártico emisferio, para imitar los golpes de su lança. obedecer su estilo por maestro 4.

El segundo, en $E$ l peregrino indiano ${ }^{5}$, del citado Saavedra Guzmán:

El que busca de amor $y$ de ventura exe[m]plos dignos de inmortal memoria mire la dulce $y$ verdadera historia que del tiempo $y$ de olvido está segura.

Vera también al biuo la pintura de aquella memorable $y$ gran vitoria que dio a Cortés y a España ta[n]ta sloria, $y$ al mexicano, muerte $y$ sepoltura.

Hallará en don Antonio, juntamente, vn Marte con la espada, y con la pluma vn nueuo Apolo, digno de renombre.

iHonor y lustre ${ }^{\circ}$ de la edad presente: de embidia de tu fama se consuma el que no te tuuiere por más que ho[m]bre!

3 Madrid, Pedro Madrigal, 1599, preliminares. B. N. = Biblioteca Nacional de Madrid : R-6.585. Edito todos los textos actualizando la puntuación, acentuación y uso de mayúsculas. En lo demás, respeto totalmente la ortografía.

- Como en las tres primeras estrofas se dirige directamente al autor, dichoso $t u$, podrían ser anómalos los dos $s u$ del último terceto.

5 Madrid, Pedro Madrigal, 1599, preliminares. B. N. R-11.597.

- IIiustre? Las dos formas aparecen en Villamediana y Góngora. 
Ambos sonetos nos permiten sorprender los primeros ensayos poéticos del Conde, y asegurar tres datos: que estaba, lo que era corriente en la época, en disposición de escribir versos publicables desde la adolescencia; que fue Tribaldos de Toledo, su maestro, quien 1e introdujo en la poesía militante, y que el discípulo conocía ya la obra de Góngora o, al menos, se iniciaba en una línea de coincidencias estilísticas con él.

E1 Conde fue bautizado el 26 de agosto de 1582. Las tasas de los libros de Vargas y Saavedra están fechadas a 3 de abril y a 17 de marzo, respectivamente, y el primero tiene dada la aprobación del 19 de octubre de 1597. De quince a dieciséis años tenía, pues, al escribir estos poemas, lo que presupone una labor de aprendizaje serio desde meses antes.

Al frente de la obra de Vargas Machuca aparece también un soneto de Luis Tribaldos de Toledo. Como sabemos con toda certeza - cosa que no ocurre con Jiménez Patón ${ }^{7}$ - que fue el preceptor del Conde, es evidente que fue el maestro quien le llevó a la poesía militante. ¿Qué poetas aconsejaría a su discípulo? Desde luego, los clásicos y toda la corriente que va de Petrarca a Herrera y, dentro de ella, a Francisco de Figueroa. a quien tanto admiraba y del que luego sería editor, regalándole el códice a Villamediana ${ }^{8}$. $\mathrm{Y}$, en efecto, en esta línea intimista está su poesía amorosa. Pero parece que el discípulo había leído, antes de entrar en el siglo de las Soledades, a don Luis de Góngora. Estos dos sonetos pueden ser una prueba de ello.

Siendo ambas dos composiciones laudatorias, a la hora de buscar el influjo de Góngora en ellas era lógico empezar por leer aquellos sonetos en los que, antes de 1599, don Luis hubiese escrito en elogio de algún poeta. Góngora había publicado para entonces un soneto al frente de La Austriada de Rufo ${ }^{\circ}$. Un análisis un tanto detenido nos permitirá acercar

7 Se viene repitiendo tradicionalmente que el Conde fue discípulo de Jiménez Patón y Tribaldos de Toledo. De que lo fuese del primero yo no he podido encontrar prueba concreta ninguna. Se ha debido suponer teniendo en cuenta que Villamediana hizo al preceptor de Villanueva de los Infantes Correo Mayor del lugar donde explicaba, y que éste le dedicó a su protector el Mercurius Trimegistus. Que Tribaldos fue su maestro, es seguro: lo dice él mismo en el prólogo que puso a las obras de Figueroa, de las que fue editor (Lisboa, 1626). A este testimonio puedo añadir el de MrLo, quien, en su Hospital das Letras (en sus Apologos dialogaes, Lisboa, 1721, págs. 337-340), al ocuparse de Villamediana, recuerda que estudió con Tribaldos.

8 Lo dice Tribaldos en el prólogo a Figueroa, citado.

9 MILLÉ, 236. El soneto es de 15846 1585. V, la nota de Millé. 
los dos sonetos villamedianinos al del cordobés, e incluso reflejar un posible influjo directo. Veamos el que empieza: Gloria y honor del Indico Occidente.

El tema es el mismo: alabanza a dos escritores (Rufo y Vargas Machuca), que tratan en sus obras de asuntos bélicos (de don Juan de Austria y de las tácticas militares en América). Góngora opta, porque es maestro en las dualidades ideológicas y sintácticas ${ }^{\mathbf{1 0}}$, por elogiar al autor y al personaje del libro: uno es Apolo; otro, Marte. Villamediana no tenía a mano esta dualidad, pero descompone a su autor - militar de profesión- en dos, el escritor y el soldado, y tiene así su doble punto de vista del tema.

Nos encontramos en Góngora:

él de la espada del sangriento Marte, vos en la lira del sagrado Apolo (vs. 13-14).

y

pues fuisteis cada cual único en su arte:

él solo en armas, vos en letras solo (vs. 10-11).

Los cuatro versos, dos a dos, se aparejan a éstos del Conde:

en los trances de Marte valeroso, $y$ en los actos de Palas eloquente (vs. 3-4).

y

pues tu raro valor $y$ braço alcança

en arte $y$ gloria militar tan diestro (vs 10-11).

Marte sangriento, frente a Marte valeroso; Apolo en la lira, frente a Palas en la elocuencia; pues (nótese la conjunción típicamente gongorina) en arte: ínico en las armas uno, en las letras otro; pues: raro el uno en arte, raro el otro en gloria militar.

Ahora ya nos sorprende menos encontrar esta semejanza:

ciñe de lauro a cada cual la frente (v. 8).

cuya inuencible frente

ciñe la flor del lauro victorioso (vs. 5-6).

Donde el cultismo lauro es bastante llamativo; había sido empleado por don Luis otras dos veces en su primera época. Y al recorrer la coin-

10 Dámaso Alonso, en La correlación en la poesía de Góngora (Estudios y ensayos gongorinos, Madrid, 1955, pág. 239), incluye este soneto en la lista de los correlativos, aunque no lo comenta. 
cidencia léxica resulta : ambos usan (la mayoría son cultismos) : gloria, arte. Marte, Apolo (Palas), fama, lauro, frente.

La estrustura de los sonetos es equivalente: ambos se dirigen al autor: cantaste, Rufo; dichoso tú. En ambos, la dualidad persiste en los ́litimos versos de cada cuarteto y cada terceto (cito primero a Góngora y debajo, y a la derecha, a Villamediana) :

que esta dudosa entre los dos la gloria

y a cuál se deba dar ninguno siente

en los trances de Marte valeroso

$y$ en los actos de Palas eloquente

ciñe de lauro a cada cual la frente

deuido en Corte al escritor famoso

como en campaña al general valiente

pues fuisteis cada cual unico en arte:

él solo en armas, vos en letras solo.

pues tu raro valor $y$ braço alcança

en arte y gloria militar tan diestro

él de la espada del sangriento Marte

vos de la lira del sagrado Apolo

para imitar los golpes de su lanza, obedecer su estilo por maestro.

Como puede observarse, el Conde - que para mí es el poeta que mejor supo, y con originalidad, calcar las formas gongorinas- despliega ya una habilidad extraordinaria desde su adolescencia en ceñirse al gongorismo. Sin embargo, hay dos razones por las que todavía en este soneto está muy lejos del cordobés: primero, porque Villamediana expresa su juventud -educado para noble y militar (luego fue Maestre de Campo en Lombardía) - en muchos lugares de su soneto : primero, puede sentir una verdadera atracción por ese general indiano que es a la vez escritor; segundo, porque es torpe en darnos esa dualidad. Sólo la da de forma 1ógica, mientras que Góngora la lleva dentro de sus palabras hasta darla a los lectores, por medio de: dudosa, entre los dos, a cuál, cada cual, que de los dos, cada cual, igualmente.

El soneto $E l$ que busca de amor $y$ de ventura, aunque menos, tiene bastante analogía con el gongorino, y también con el otro de Villamediana. Aquí no se mantiene la dualidad tan clara, aunque era este tema más propicio a utilizarla, ya que se elogia a un escritor que trata en 
verso las hazañas de Hernán Cortés, tema análogo al de Góngora. Véase de nuevo a Apolo y Marte:

un Marte con la espada y con la pluma

vn nuevo Apolo,

Y todavía dos coincidencias más, aunque se den en un terreno donde el tópico es muy frecuente : ambos riman en roria, y con los mismos cuatro vocablos: historia, gloria, memoria, victoria. $\mathrm{Y}$ ambos coinciden en :

\title{
del tiempo y del olvido haya victoria \\ que de tiempo y oluido está segura
}

Si el Conde no imitó ya en 1598-99 a Góngora, al menos coincide con la línea cultista totalmente $\mathrm{y}$ con las dualidades de don Luis.

\section{2}

1611.- - Hasta doce años después no vuelve, que yo sepa ${ }^{11}$, a publicar otro poema. De nuevo lo hace en alabanza de un libro, de El buen republico ${ }^{12}$, de aquel interesante escritor a quien llamaron sus contemporáneos el caballero de milagro, Agustín de Rojas Villandrado. Es el siguiente :

\author{
Sea para bien, en hora buena sea. \\ diuino Rojas, el rezién nacido, \\ que tal hijo de ingenio ha merecido \\ que esculpido en mil láminas se vea. \\ Plega a los cielos que la excelsa idea \\ del Repúblico llegue el apellido \\ a donde desterrándose el oluido \\ de Daphne ingrata su laurel possea.
}

11 En 1605 estaba en Valladolid, entonces Corte, el escritor portugués Pinheirn da Veiga, que escribía su Fastiginia. En esta obra copió el soneto El que fuere dichoso será amado, atribuyéndolo al Conde. Pero este libro no se editó entonces, sino que quedó inédito hasta nuestro siglo, en el que apareció : en portugués, en 1911, y en castellano, en 1916. V. N. A. Corrés: La muerte del Conde de Villamediana, Valladolid, 1928, pág. 50. F1 soneto se editó por primera vez, en El Condeduque de Olivares y el Rey Felipe IV. Cádiz, 1846, pág. 53, por don A porfo nF: Castro, a nombre del Conde. También se le atribuye en el manuscrito de la $\mathrm{B}$. N. R-18.405, pero no en el 17.719, que lo hace al Conde de Salinas.

12 Salamanca, Antonia Ramírez, 1611. B. N. R-6.521. Hay segunda edición, de 1620 . 
Ensancha, Mançanares, tus riheras, donde tu nieto con amor recibas, hijo de un hijo de tu margen bella.

Aqui viene a servirse muy de veras, amparale piadoso, assí tú viuas eternos años con feliz estrella.

Aquella cierta ingenuidad de sus dos sonetos adolescentes se ha transformado en ingenio. El poeta felicita al autor por el nuevo hijo de su mente, y pide al Manzanares, abuelo de la criatura, ya que es padre de Rojas, natural de Madrid, que le ampare y reciba con amor.

\section{8}

1617-1618. - Las cuatro octavas que a continuación copio se editaron en pliego suelto del que se ha conservado un ejemplar, encuadernado con otros papeles, en el manuscrito 3.657 de la Biblioteca Nacional madrileña. No trae ninguna indicación tipográfica, y está impreso con esmero ${ }^{13}$. Llevan por título y dicen :

\section{ESTANCIAS / Al Principe Nuestro Señor}

Estas armas, Señor, en juueniles años de fe $y$ valor alimentadas, para afrenta de Alcides $y$ de Achiles, oy el cielo las tiene reseruadas; Athlas descanso espera en las viriles fuerças que, contra el Asia exercitadas, quando el azero fulminante vibres, las aguas del Iordán nos hara libres.

Ya Tethys, entre conchas erythreas, benigna aguarda el militar portento, porque inspiradas de aura dulce veas tus velas coronar su instable argento; las generosas plantas idumeas crecen, insinuando el vencimiento, flexibles, arrogandose tu mano, Alexandro español, César christiano.

13 Caja de escritura : $233 \times 127 \mathrm{~mm}$., en un folio de $310 \times 210 \mathrm{~mm}$. PÉreZ DE Guzmán las editó, sin indicación alguna de fecha, autenticidad y procedencia, en Los principes de la poesía española, Madrid, 1892, págs. 187 y sigs. B. N. R-3.025. Este libro es una tirada aparte de lo que antes había venido apareciendo en la Revista Contemporánea, desde 1889 a 1892. 


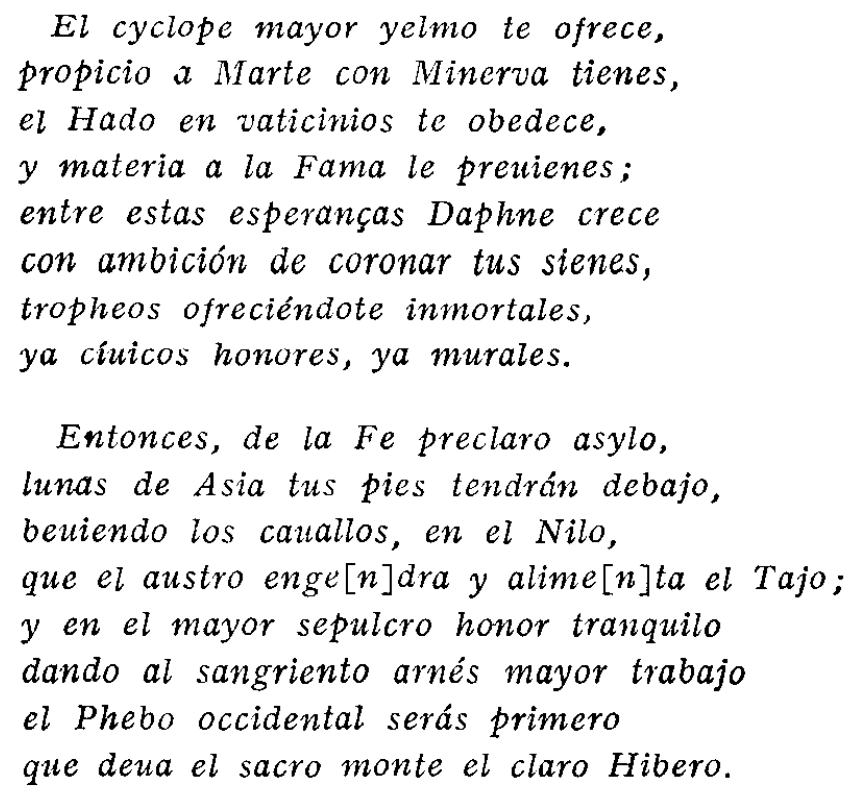

A la vuelta del folio, una mano de la época ha escrito: Villamediana al Armarse su Al. el Pe. Luego volveremos ampliamente sobre esta atribución, pero antes, admitiéndola, vamos a partir de ella para averiguar a qué príncipe se refiere y en qué fecha se escribieron. El Conde sólo conoció a dos herederos de la corona española antes de reinar : a Felipe III y a Felipe IV. Ess más fácil, mucho más, que se trate del segundo, pues al primero, como príncipe, lo conoció siendo muy niño para escribir tan perfectas octavas en su homenaje. Puestas así las cosas, se trataba de buscar una ceremonia a la que Felipe IV, siendo príncipe, hubiese acudido armado (o bien la misma ceremonia en que fue armado caballero). Una lectura de las Relaciones ${ }^{14}$, de Alenda, desde el año 1615 -en que tenía diez años el Príncipe- en adelante, nos hace encontrarnos con un impreso que describe así (núm. 690) :

(1618) Al Príncipe nuestro Señor en el torneo.

Bien muestras gran Felipe, lo que espera el Orbe en ti; pues el pesado acero...

Son cuatro octavas escritas por Francisco López de Zárate, e incluídas en la colección de sus Varias poesías, impresa en 1619, por la viuda de Alonso Martín de Balvoa (Madrid), en 8.

Además de callarse el nombre del Príncipe, se nos deja en la duda de cuál fue ese torneo y con qué motivo se celebró; omi-

14 Relaciones de solemnidades y fiestas públicas de España, Madrid, 1903. 
siones todas muy de lamentar en nuestros antiguos vates. Sobre el primer punto, sin embargo, se nos suministra la luz necesaria en la reedición, copiosamente aumentada, que hizo de aquellas poesías en 1651 la impresora de Alcalá, María Fernández, en cuyo tomo, pág. 55, se reproducen las mismas octavas con este mismo epígrafe :

Al Rey nuestro Señor Don Felipe IIII, siendo Príncipe en un torneo.

El lector habrá podido comprobar la semejanza entre el impreso citado por mí y el descrito por don Jenaro Alenda: dos pliegos sueltos, de la misma época, sin atribuir y sin dato tipográfico alguno, conteniendo un texto al mismo asunto y, sobre todo, teniendo el mismo metro y el mismo número de estrofas; tal semejanza está claramente diciendo que se imprimieron en elogio del Príncipe para la misma ocasión y que, tal vez, haya otras de otros poetas, escritas todas de común acuerdo para dar realce a la fiesta. De ser así, para fechar las que a nosotros aquí nos interesan, nos valen todas las indagaciones que hizo Alenda. La aprobaciọ́n de las obras de López de Zárate tiene fecha de 29 de noviembre de 1618. En ese año, el día 22 de abril -lo sabemos por las cartas de Felipe III a su hija Doña Ana, Reina de Francia, que extracta Alenda- se celebró un suntuoso torneo en el que actuaron el Príncipe y sus hermanos. Está claro que para ese torneo escribió Zárate ${ }^{15}$ sus estancias, y vemos que, ante la total semejanza de nuestro caso, con gran probabilidad, también las nuestras se escribieron para esa fecha.

Pero queda otra posibilidad: parece querer decir -aunque puede ser que no supiese con exactitud el detalle- el anónimo atribuidor, o poder decir, al menos, con sus palabras Al Armarse, que fueron escritas con motivo de la ceremonia en que se armó caballero a Felipe IV. He buscado en Céspedes y Meneses ${ }^{\mathbf{1 6}}$, y en otros historiadores modernos, y no he encontrado este dato. Pero los infantes solían armarse caballeros no antes de los once años. Felipe IV tenía once años en 1616 y era caballero - he-

15 Equivocadamente se atribuyen a Lope de Vega estas octavas en el tomo III, página 433, de Obras sueltas, y en el tomo de Obras no dramáticas, de Rivadeneyra, pág. 349. También se editó como de Lope (Obras sueltas, III, pág. 483 ; Obras no dramáticas, pág. 377) la Silva a la ciudad de Logroño, de Zárate. Véase, además de las ediciones que cita Alenda, la moderna de Srmón DÍAz, Madrid, 1947, 2 vols. Biblioteca de antiguos libros hispánicos, del C. S. I. C.

10 Historia de Don Felipe IV, Rey de las Españas..., Madrid, 1631. 
mos visto que actuó en un torneo en abril de 1618-. Entre estas fechas hemos de fijar las octavas del Conde, aunque yo estoy casi seguro de que se escribieron concretamente para ese torneo. Si son de Villamediana, esta acotación de tiempo se ve confirmada con su biografía. A finales de 1616 había ya regresado de Italia, y en 1617 lo encontramos en Toledo escribiendo su poema en octavas Fábula de Faetón. En el mes de noviembre de 1618 había perdido de nuevo el favor real y era desterrado de la Corte ${ }^{17}$.

Hemos, pues, fechado las cuatro octavas con bastante precisión, e incluso tenemos gran fundamento para pensar que conocemos la fecha con exactitud, incluso de días. Queda por insistir en la atribución. Tenemos la prueba de esa atribución anónima, no desmentida nunca por nadie, y sabemos que, precisamente en esos dos años en que se escribieron, 1617 ó 1618, es cuando el Conde estaba de cortesano, entre su viaje a Italia y su último destierro. Otras pruebas encontramos al cotejar las octavas con otras composiciones del Conde. En primer lugar, Villamediana utilizó en muchas ocasiones la octava, estrofa que, como buen gongorino, dominaba: sus fábulas de Apolo y Dafne y de Faetón están escritas en este metro, así como varias composiciones breves y la loa de La Gloria de Niquea, a la que en seguida nos vamos a referir.

Villamediana escribió numerosas composiciones en alabanza de Felipe IV y sus hermanos. Los números siguientes (citados por la primera edición) de sus sonetos Líricos tienen este asunto:

II : Emulo al Sol saldrá del cielo esperio (Al Príncipe de España).

IV: Para dar lei al mundo al mundo venga (Al nacimiento del Príncipe de España).

XX: Tiempla lira feliz, sacro mancebo (sin epígrafe, al Príncipe).

XXII : Crece planta feliz, ay esperança (Al nacimiento del Señor Infante Carlos) -o tal vez al Príncipe-.

XXIV: Deste que con las ondas del cabello (sin epígrafe, a uno de los Infantes, seguramente al Príncipe).

XXVI : Gloriosa cuna al bien nacido Infarte (sin epígrafe, a uno de los Infantes).

17 Sabemos la fecha y el lugar donde escribió el Faetón por el manuscrito de Chacón (v. Milı́, núms. 177, 344 y pág. 1126). Conocemos la fecha del destierro por un noticiero anónimo (v. Cotarelo, ob. cit., pág. 78) y por la fecha en que firma la carta-prólogo que más adelante edito. 
XXVII : Crece, o pimpollo tierno, entre leales (Al Rei nuestro Señor recién nacido).

$\mathrm{XXX}$ : Oy que sacra púrpura ascendiente (sin epígrafe, al ser nombrado Cardenal el Infante don Fernando).

XLVII : Si el sol oi nuestro azero luminoso (sin epígrafe, con toda claridad al Cardenal-Infante).

XIVIII : Esta cuna feliz de tus abuelos (sin epígrafe, al Príncipe). No hace falta buscar con mucho detenimiento en estos sonetos para encontrar en ellos la misma idea de las octavas : la idea imperial de un universo unido en la fe de Cristo, bajo el mando de Felipe IV. Tanto es así, que todas las frases de las estancias se pueden hallar en los sonetos números :

II : Al Asia librará de cautiverio (octs. v. 6-8).

IV : E1 Atlante gentil... (octs. v. 5).

IV : Asistan las tres gracias y Belona (octs. estrofa 3..$^{\mathrm{a}}$ ).

IV : Que con estos presagios su Fortuna (octs. estrofa 3. ${ }^{a}$ ).

$\mathrm{X}$ : A sustentar el peso peligroso que teme Alcides y que gime Atlante (octs. v. 3 y 5).

$\mathrm{XX}$ : Que joven en virtudes ya viriles Atlante serás claro, Alcides nuevo (octs. v. 3 y 5).

XXII : Pues ya menguar su luna el Asia siente (octs. v. 6 y 26).

XXII : El gran sepulcro adorarás, pendiente en él tu arnés manchado en su vengança.

Esperio sol... (octs. v. 29-30).

XXII : Coronarás el soberano monte (octs. v. 32).

XXII : Serás pio Jasón del César sacro (octs. v. 16).

XXVI : En su descanso el fatigado Atlante (octs. v. 5).

XXVI : Rayos dé Marte, y sol dé Citherea, leche de honor te dé Bolona, Astrea asuntos dignos que la fama cante (octs. estrofa $3 .^{a}$ ).

Aunque varias de estas expresiones son tópicos de la época, queda bien manifiesto cómo Villamediana tenía unas ideas fijas y una forma de decirlas a la hora de cantar al príncipe de España. Pero más interés tiene comparar, con las octavas en cuestión, las de la loa de La Gloria de Niquea. Dámaso Alonso demostró ya cómo Angulo y Pulgar, que había dado pie a Alfonso Reyes para pensar que la loa era de Góngora, no era digno de excesivo crédito ${ }^{18}$. Demostró también que en la loa hay muchos ver-

18 Crédito atribuible al gongorista don Martín de Angulo y Pulgar (en sus Estudios y ensayos gongorinos, Madrid, Gredos, 1955, págs. 413-453). 
sos calcados de Góngora. Este casi nunca se repite, y el Conde, con mucha frecuencia (a la docena de casos que da Dámaso Alonso podríamos añadir varios), sí que toma versos de su maestro. Y como, por otra parte, el discípulo había escrito octavas tan buenas, en algunos casos, como las de Góngora, quedaba claro que no debían de salir las octavas de la loa de La Gloria de Niquea para colocarlas entre las composiciones del cordobés. Veamos la identidad que existe entre ciertos pasajes de la loa escrita para felicitar a Felipe IV en su decimoséptimo cumpleaños y las Estancias en su honor al armarse caballero, o al ir a un torneo. Hay dos versos de la loa que están idénticos en las estancias :

entre estas esperanças Dafne crece

con ambición de coronar tus sienes

(Octs. v. 21-22 : La Gloria de Niquea, Obras, pág. 14)

$\mathrm{Y}$ las octavas 2 y 4 del pliego suelto vuelven a estar en la comedia con muy parecidas palabras :

\footnotetext{
Ambos te cedera mares Neptuno, $y$ desde Calpe igualmente veremos velas mil tuyas coronar al uno $y$ encanecer el otro iguales remos.

Tus trompas oyrá presto esclarecidas libre por ti, Jerusalen sagrada, $y$ en sus fuentes, aun oi mal conocidas, el Nilo beverás en su celada.
}

(Obras, pág. 12)

De todo lo expuesto en este tercer apartado se deduce :

1) Que las octavas son de Villamediana, porque a él se atribuyen en el pliego por una mano de la época, sin que hasta la fecha sepamos que se hayan tenido por obra de otro, en ningún tiempo; porque en la fecha en que están escritas él estaba en la Corte; porque en ellas se dicen las mismas cosas que él había expresado muchas veces, con las mismas palabras, incluso.

2) Que la fecha en que las escribió está entre 1617 y 1618, y hasta es muy probable que sea la de abril de 1618.

3) Que el Conde, del que se había dicho, con razón, que repite versos de Góngora, se repite a sí mismo con cierta frecuencia.

4) Que la loa de La Gloria de Niquea es, en efecto, obra suya.

5) Que Villamediana es un poeta imperial en muchas ocasiones: un solo reino en la fe de Cristo al mando de los Austrias, que liberarán su 
sepulcro y tomarán Jerusalén. En este sentido vale la pena citar todavía estos versos suyos, que recuerdan totalmente al fanıoso soneto de Acuña:

Vno el ovil, una la lei perfeta

avrá vn solo pastor $y$ vn solo Inperio.

(Obras, pág. 70)

Le dice a Felipe IV, príncipe. Y en otra ocasión :

Ceñira todo el orbe como zona quando una grei y un solo pastor tenga.

(Obras, pág. 71)

Sin duda alguna que esto es siglo xvI, solemnidad y universo, el haz de la poesía villamedianina; el envés, que lo hacen harroco, son sus sátiras políticas y personales, plebeyas e ingeniosas, metáforas alegres de un desengaño.

1618. - Son verdaderamente exiguos los restos que hemos conservado de la prosa del Conde, ya que, menos una, se han perdido todas sus cartas. Nos han quedado las prosas siguientes :

1612. - Cartel de un torneo, en colaboración con cuatro caballeros ${ }^{19}$.

¿1615 ?-Carta a un embajador de Florencia ${ }^{20}$.

1618.-La epístola-prólogo que edito a continuación.

19 No he visto este cartel, que cita Croce con otras noticias sobre el torneo, tomadas de una Descrittione del sontuoso torneo fatto nella fidelissima cittd di Napoli l'anno MDCXII con la relazione di molte altre feste per allegrezza degli Reggi Accasamenti seguiti fra le Potentissime Corone Spagna e Francia... racolta dal dottor Francesco Valentini... (Nápoles, 1612). V. CROCE : Due illustrazioni al "Viaje del Parnaso" del Cervantes (en Homenaje a Menéndez y Pelayo, Madrid, 1899, I, pág. 189).

20 Editada por Cotarelo, ob. cit., págs. 43-48. Como complemento a estas cuatro prosas, voy a contar aquí un chiste del Conde, hasta ahora desconocido. Se conserva en un Capitulo de auisos venidos con Extraordinario de Madrid que llegó a seis de Julio de 1621 (ms. 290 de la B. N., fol. 17 r.). Refiere el anónimo noticiero que, al saberse la noticia de que al de Alcañices lo hacían de la Cámara, «Villamediana ha hecho vn agudo pensamiento diciendo que tienen mucho que mirar en esta elección, porque si le meten allá puede temer que empeñe vn Infante, como ha vinido con tantas trampas $y$ enrredos». 
1622.- - Ia descripción de Aranjuez y las anotaciones de la comedia que se publicaron con La Gloria de Niquea ${ }^{21}$.

Debió de unir una larga amistad a Villamediana con Vargas Machuca. Ya lo vimos, de joven, elogiar un libro del general, en 1599. Ahora, en 1618, éste le pide un prólogo para su libro Teórica y exercicios de la Gineta $^{22}$, que Villamediana escribió en los primeros meses de su úlimo destierro. Es esta carta precisamente el documento que nos dice con más seriedad que visitó Sigüenza durante su apartamiento de la Corte, y una comprobación de que es suya la sátira a los canónigos de esa ciudad:

\section{Llegué leguas caminadas por dar descanso a mis plantas al lugar de menos santas $y$ de más canonizadas ${ }^{23}$.}

E1 autor del libro sobre equitación sabía que le pedía el prólogo a uno de los mejores jinetes de la época. T'enemos muchos datos para ilustrar esta afición por los caballos, que le venía de su padre, y que tan relacionada estaba con su oficio de Correo Mayor del Reino. Es muy conocido el soneto de Góngora Al Conde de Villamediana, celebrando el gusto que tuvo en diamantes, pinturas y caballos. Tenemos muchas noticias de la habilidad con que toreaba a caballo, y en sus versos hay un par de hallazgos que sólo se explican en un buen jinete ${ }^{24}$. Salcedo Coronel, al ilustrar el soneto que he citado de Góngora, cuenta: "Esstremóse... en adquirir los mejores caballos $\mathrm{q}[\mathrm{ue}]$ ha tenido cauallero, ni señor en España; la mayor grandeza suya fue (como yo le oi muchas veces) $q[u e]$ nunca vendió cauallo, porque, o los daua, o le morían en su (asa) ${ }^{25}$.

21 Obras, 1629, págs. 1-54.

22 Madrid, Diego Flamenco, 1619, preliminares. B. N. R-7.830. Del libro hay otras dos ediciones, de 1600 y de 1621 (ésta, abreviada). En ninguna de estas dos aparece el prólogo de Villamediana. Puntuo y acentuo el texto y deshago las abre. viaturas.

23 La editó por primera vez, en el Semanario Pintoresco (1850, núm. 39, página 307), NeIRA DE Mosquera, con el siguiente epígrafe: Llegó a la ciudad de Sigüenza $y$, para mostrar que las mujeres de alli eran damas de los canónigos, improvisó esta redondilla.

24 Véase mi artículo Notas a Villamediana al margen de Góngora (en Cuadernos de Arte y Pensamiento, núm. 1, mayo 1959, págs. 31-34).

25 Obras de Don Luis de Góngora comentadas... Tomo II, Madrid, Diego Díaz de la Carrera, 1644, pág. 238. Sin embargo, sabemos que, al menos en una ocasión, vendió un caballo, aunque joven, si atendemos al precio de la operación : al Conde de Salinas, por 300 escudos de oro. 
En la epístola se muestra no sólo entusiasta de los equinos, sino co nocedor de multitud de datos eruditos sobre ellos. Tiene también interés la breve historia de los correos que hace, y es pena que no insista más en esto, ya que como Correo Mayor - cargo que tradicionalmente ocupaba su familia en diferentes partes de Europa- la conocería muy bien. Además es un documento inapreciable, junto con la citada carta al Eimbajador de Florencia, para ver su concepto del honor y de la nobleza, tema demasiado extenso para este trabajo y que desarrollo actualmente en otro lugar.

[fol. 4r. s. n.] EPISTOLA DEL Conde de Villamediana, Al Auctor.

Aviendo con atención passado los ojos por este tratado de la Gineta, hallo q[ue] v. m. tiene gran[n]demente obligados los caualleros de ambos orbes, por auer cumplido, con tan general satisfación, con lo que deue a quién es, no sólo obrando, como maestro, las materias desta professión de cauallería, para que siguiendo su exemplo y doctrina ningún español dexe de arribar al palio de la virtud heroyca, política y militar. Que aunque no es de todos correspon- [fol. 4v. s. n.] der al reno[m]bre y calidad de sus mayores con bastante equivalencia, pues no siempre con la sangre Naturaleza infunde la capacidad, fuerças y ánimo generoso de los passados, en v. m. ha sido esto ta[n] superior que podemos dudar quié[n] aya dado mayor lustre a su alcuña, co[n] ser la de v. m. ta[n] lustrosa, como luego veremos. Que es cosa justificada quando nuestros méritos excedieren la soberanía de nuestros predecessores, nos tengan la obligación que les deuemos tener, quando los suyos se adelanta[n] a los nuestros, pues no ay por qué yo no pueda honrar a mis abuelos, o con paridad en valor, o con excesso, como ellos lo pudiero[n] hazer conmigo. Que [fol. 5r. s. n.] a desiguales merecimientos, en toda buena policía y justicia, se deue[n] premios desiguales, y qua[n]do v. m. no tuaiera otra demostración para prueua de su nobleza, bastará este indicio de ser ta[n] apasionado como diestro en el manejo de $\operatorname{ta}[\mathrm{n}]$ preciado y gallardo animal como el cauallo, cuya nobleza de raça es cosa cierta que la ay y huuo antiguame[n]te, como entre los ho[m]bres, hasta arribar a diuinidad, visto que Neptuno, monarcha y deidad del mar (según el gentilismo), fue el primer productor del cauallo.

Que sin el que, tocando la tierra, hizo salir bufando en la competencia q[ue] tuuo con Palas sobre el poner no[m]bre a la ciudad de Athenas, hiriendo otra [fol. 5v. s. n.] uez en ella con su tridente produxo a Xantho y Cyllaro, de que hizo presente a Iuno, y ella a Cástor y Pólux, tan célebres heróes (sic) que aun los $\mathrm{q}[\mathrm{ue}]$ gouernaron sus carros fundaron en Sarmacia los pueblos Heníochos, cuyos no[m]bres fuero[n] Telechín y Amphito. El mismo Neptuno engendr6 al generoso cauallo Arión que por esto Homero lo llama diuino, y Propercio dize q[ue] hablaua y tenía uso de razón. Estacio le compara a la inconstancia del mar alterado en inuierno, al qual se atribuye la llanura, conuenie[n]te al agua y a los cauallos. Y a esta causa, dan el mismo nombre al piloto $\mathrm{q}[\mathrm{ue}]$ al gouernador del cauallo, que, como a éste con la rie[n]da, rige al baxel [fol. 6r. s. n.] con el gouernalle. Desta nobleza resulta que son estos animales tan magnánimos y de considerables respetos q[ue] vno por auerle el señor engañado, tapándole los ojos para que cubriese a su madre, co[n] desseo de su raça, cuando se vio descubierto, quedó tan desdeñosc 
del caso $\mathrm{q}[\mathrm{ue}]$ se arrojb́ a vn gran despeñadero y hizo pedaços. $\mathrm{Y}$ otro, de Iordan Vrsino, adelantado de Córcega, por auerle quitado de la silla y jaezes, y puesto a tirar vn carretón, arremetió con él y saltó en vna sima de gran profundidad. Donde, no sin causa, dize Homero q[ue] Apolo se preció de guardar las yeguas del Rey Admeto de Thessalia, y en Pieria las de Eumelo, que era[n] iguales en [fol. 6v. s. n.] velocidad a las aues. Cuéntase que entre los Thessalios, los primeros que con destreza domaron cauallos fueron los Peletronios; pero lo más cierto es $\mathrm{q}[\mathrm{ue}]$ aquel grande y heroyco cauallero Bellerophonte, recibie[n]do al Pegaso de Neptuno, y después en sueños vn freno de oro, de mano de Minerua, le enfrenó y domó, y con él acabó la dificil empressa de la Chimera, en Lycia. Y al fin, alumbrado por gracia del cielo, enseñó esta doctrina entre los hombres, auiéndosela comunicado Neptuno, quien dize Nestor que mostró manejar cauallos a su hijo Antiocho, como Iupiter entrar co[n] ellos en las batallas. Por el qual beneficio llamaron los griegos [fol. 7r. s. n.] a Neptuno, Hippio. Los no[m]bres que de ciudades, montes y regiones del cauallo ha[n] tomado, son sin número, $q[u e]$ aun nuestros nauega[n]tes, en la carrera de las Indias, no[m]bran por famoso el golfo de las Yeguas. Y baste $\mathrm{q}[\mathrm{ue}] \mathrm{Homero}$ qua[n]do quiere dar epíteto honroso a Hector, Ajaz, Diomedes o Néstor, echa mano del hipodamo $q[\mathrm{ue}]$ es domador de cauallos; 10 mismo q[ue] Virgilio, a su imitación, llama a Mesapo hijo de Neptuno, a Poco, Rey de los latinos, $\mathrm{y}$ a Ausentino, hijo de Hércules. $\mathrm{Y}$ grandes príncipes en todas las naciones se han preciado del no[m]bre de Philipes, $\mathrm{q}[\mathrm{ue}]$ denota amigos de cauallos, por ser precisame[n]te este animal de suma importancia a las personas [fol. $7 \mathrm{v}$. s. n.] más grandiosas, y generalme[n]te a todo el género humano, por el grande socorro $\mathrm{q}[\mathrm{ue}]$ halla en él, assí para escusar grandes peligros, como para alca[n]çar nobles vitorias y renombre inmortal; pues por ser tan belicoso y leal, le tienen los ho[m]bres nobles y valerosos con título de dignidad preheminente entre todos los demás.

Que aú[n] en el estado real, lo más q[ue] se puede loar vn príncipe es diziendo $\mathrm{q}[\mathrm{ue}]$ es buen cauallero, vocablo en quien se incluyen valor $\mathrm{y}$ virtud. Y no sólo de su fortaleza, mas de su ligereza, resulta tanta y $t a[n]$ necessaria vtilidad que no tienen los Reyes tan solícito cuydado ni gusto en otro algún ministerio de su seruicio como en el del [fol. 8r. s. n.] general de las postas, con quie[n] en breuíssimo espacio de tie[m]po tienen auiso de distantíssimos lugares, y aduierten de lo q[ue] importa al gouierno de sus estados. Inuención antiquíssima entre los persas cuyo autor fue Xerxes, según Cleomedes, quando hazía guerra a la Grecia, disponiéndolas de modo que con vna vez se entendían de la vna a la otra, y en menos de dos días sabía en Persia qua[n]to passaua en Athenas y Lacedemonia. Vsó las postas Pyrro, Rey de Epiro, primero entre los griegos, y Augusto en Roma, y después los demás emperadores. El gra[n] Cham de Tartaria, escriue Paulo Venteo, q[ue] las tiene por todo su Imperio, de 25 a 25 millas, au[n] [fol. 8v. s. n.] en los desiertos, do[n]de muda[n]do cauallos, haze[n] en vn día 200 y 500 millas. Esta vsança se renouó en Italia en tie[m]po de los Vizcondes de Milá[n], y Luis XI las introduxo en Fra[n]cia por su vtilidad.

$\mathrm{Ha}[\mathrm{n}]$ sido en el mundo algunos cauallos ta[n] ligeros $\mathrm{q}[\mathrm{ue}]$ co[m]pitieron co[n] el viento. Probo, emperador, en la guerra de los Alanos, huuo vno q[ue] corría cien millas al día, y duraua diez sin cansarse. Syla, y vn rey de Dinamarca, tuuie$\mathrm{ro}[\mathrm{n}]$ dos de estraña velozidad $\mathrm{y}$ hermosura. Innumerables fueron los $\mathrm{q}[\mathrm{ue}]$ en la antigüedad alca[n]çaro[n] reno[m]bre por esta naturaleza. De Iapón cue[n]ta Silio $\mathrm{q}[\mathrm{ue}]$ era Galiciano y dexaua en la carrera los toruellinos atrás, q[ue] allí se dize 
$\mathrm{q}$ [ue] las madres conciben del [fol. 9r. s. n.] vie[n]to zéphiro. Gargano, Teró[n], Tajo y Lamo, de tierra de Lérida, corriero[n] co[n] inco[m]parable gallardía, y Cireo afirma bolar por el ayre, antes $\mathrm{q}[\mathrm{ue}]$ correr por el suelo. Arión en poder de Adrasto, segá[n] Estacio, dexaua atrás los nublados impelidos y apremiados de vie[n]to. La fortaleza de Bucéphalo, de cuyo nombre Alexa[n]dro hizo labrar vna ciudad qua[n]do se le mataro[n] en la India, la $d[e]$ Bauieca, sobre quie[n] nuestro gran Cid Ruydiaz venció 72 batallas campales, bien celebrada va por las historias. En suma, de más de sus propicłades, no ay fiesta ni jornada de paz o guerra que sin ayuda de cauallo se pueda honrosame[n]te acabar, a cuya causa tiene[n] ta[n]tas [fol. 9v. s. n.] prerrogatiuas $q[\mathrm{ue}]$ so[n] inestimables en el $\mathrm{mu}[\mathrm{n}]$ do ; por donde, aun los teológos haze[n] ta[n]tas alegorias de su naturaleza, con los demás escritores en todas facultades. Grande no[m]bre alcançaro[n] de ho[m]bres de a cauallo los Scythas, o Tártaros, los Persas y los Tebanos, mas particularme[n]te los de Colopho[n] en Assia fueron en esto singulares, como en el arte $d[e]$ marear. De suerte $q[u e]$ qua[n]do vna guerra no se podía co[n]cluyr, con traer la cauallería de Colophó[n], luego el enemigo era roto.

A tales caualleros ha imitado v. m. en todo el discurso de su vida por mar, y tierra, porq[ue] sie[n]do hijodalgo de solar conocido, decendie[n]te del famoso Garcipérez de Vargas, media[n]te cuyo valor el [fol. 10r. s. n.] Rey don Ferna[n]do ganó a Seuilla, hermano $q[u e]$ fue de Diego Pérez de Vargas $q[u e]$ por su notoria vale[n]tía ganó el reno[m]bre de Machuca, ha seruido a su Magestad de 50 años a esta parte $c o[n]$ tanta satisfació $[n]$ como co[n]sta de las certificaciones de sus seruicios en la guerra de Granada, y en las de Leua[n]te y armadas del mar, atrauessando el Ocide[n]tal, y siendo Maestre de Campo en el nueuo Reyno de Granada, acaba[n]do algunas de sus dificultosas co[n]quistas y subie[n]do a mayor título de capitá[n] general otras muchas, y demás desto reedifica[n]do ciudades y defendie[n]do otras de apretados sitios del enemigo, y auie[n]do poblado la ciudad de Sima[n]cas en memoria de su patria, de [fol. 10v. s. n.] cuya fortaleza su padre de $\mathrm{v}$. m. fue alcaide tantos años. No hablo de los castillos de Portobelo y Rio de Chagre, q[ue] fabricó por orde[n] de Su Magestad ta[n] importa[n]tes a su real seruicio, pero no es de passar en sile[n]cio el gouierno de la Isla Margarita, do[n]de, como Capitá[n] general, fue temido de infieles y respetado de los naturales, por lo mucho $\mathrm{q}[\mathrm{u}]$ ] trabajo en su beneficio, fortifica[n]do la ciudad a su costa $\operatorname{co}[\mathrm{n}]$ vn eminente castillo, $\mathrm{y}$ otros reparos, gasta[n]do co[n] liberal mano su hazienda en su defensa, policía, y adorno $c o[n]$ qua[n]to vna ciudad para ser inexpugnable y no[m]rada en lo diuino y humano ha menester. $Y$ en su suma, después de auer escrito libros de arte militar, y exercita[n]- [fol. 11r. s. n.] do la gente de a cauallo para la guerra, como ta[n] gran soldado y ginete, dexa[n]do allí en bue[n] lugar vna carrera cerrada, donde los menos práticos se pueda[n] exercitar y salir diestros en la gineta para las ocasiones de ro[m]pimie[n]to con el enemigo q[ue] es la cosa con $\mathrm{q}[\mathrm{ue}]$ da cima y lustre a tales empressas co[n]tinuá[n]dolas desta suerte por tie[m]po infinito. $Y$ a esta causa es de estimar este trabajo sobre los más estimados de esta edad por auer discurrido, como ta[n] gran maestro en materia del manejo de los cauallos, para comá[n] vtilidad de la caua. llería castellana, $\mathrm{q}[\mathrm{ue}]$, sin duda, según la importa[n]cia deste libro, sería gra[n]de y general pérdida dexar de dar a la esta[m]pa segunda y más veces tan bue[n] acrece[n]tamiento para el de la nobleza y reno[m]bre de nuestra nació[n], la qual de derecho deuerá a v. m. lo q[ue] la griega a Xenophonte gra[n] filósofo y va- 
lie[n]te soldado $\mathrm{q}[\mathrm{ue}]$ en su idioma dexó vna obra ingeniosa de semeja[n]te exercicio q[ue] oy tenemos, a cuya imitació[n] en Italia el Carachulo, el Grisón, el Fiaschi, el Corte y el Siliceo con otros diuersos ha[n] escrito gra[n]des discursos desta loable materia de cauallería. Guarde Dios a v. m. muchos años \&c de Sigue[n]sa y de Diziembre 25 de 1618.

\section{5}

1620.-Como es bien conocido, Villamediana presentó un soneto al segundo certamen de las justas celebradas por la villa de Madrid con motivo de la beatificación de San Isidro. Se llevó el primer premio, sobresaliendo entre los sonetos escritos por Espinel, López de Zárate, Medrano, Montalbán, Calderón, etc., y fue publicado por Lope de Vega en su Justa poética y alabanzas justas que hizo la insigne villa de Madrid al bienaventurado San Isidro ${ }^{26}$. Después fue incluido en sus Obras desde la edición príncipe. E1 publicado en la justa presenta así el verso 11 : en quanto al cielo rinde alto tributo, variante que hay que tener en cuenta, pues esta versión es, sin duda, la que dio el Conde a la justa, que apareció impresa en vida de él e inmediatamente después de celebrarse.

Uno de los sonetos más famosos del Conde es, sin duda alguna, el epitafio a don Rodrigo Calderón, Este que en la fortuna más subida. Antes de publicarse en sus Obras había sido dado a conocer en el siguiente impreso:

Romance / nuevo compves- / to a la muerte de Don / Rodrigo Calderón, em que se trata / de la prisión, sentencia, muerte / que tuuo, y del despedimiento que / hizo a la hora de la muerte. I Lleua al cabo vn Soneto famoso, que tra- / ta de lo mismo. (grabado) En Lisboa. / Con todas las licencias necessarias. Por Perto Craesbeek. En el año de 1622. (Al fin) : Taxao esta folha em cinco reis, a sete de Ianeiro. / Anno 1622, Gama, Moniz ${ }^{27}$.

Madrid, Viuda de Alonso Martín, 1620, fol. 45 v. B. N. R-4.901.

27 En 4..$^{\circ}$, dos hs. Biblioteca de don Antonio Rodríguez-Moñino. V. AnTonio Pérez Gómez: Romancero de Don Rodrigo Calderón (1621-1800), Valencia, .... la fonte que mana y corre..., 1955, pág. 27. 
Creo que éste es lugar para mostrar brevemente las más importantes variantes con que el soneto ha llegado a nosotros; dos de cllas tienen interés estilístico. Los versos 1 y 2 y 9 y 10 se leen así, en la primera edición de las Obras del Conde:

1 Este que en la fortuna más subida

2 no cupo en sí, ni cupo en él su suerte

9 Que alli fio a un cuchillo los perfetos

10 medio (sic) que religión zelante ordena.

En un manuscrito de la Academia de la Historia, que publicó Rodríguez Moñino ${ }^{28}$, se encuentran las variantes que siguen :

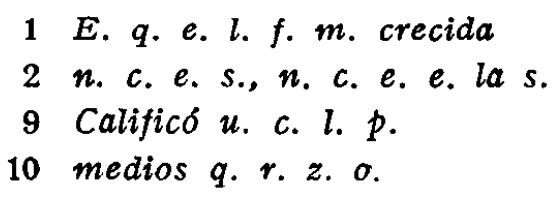

Con las variantes de los versos 2, 9 y 10 coincide Gracián al editar el soneto ${ }^{29}$. Las ediciones de Madrid no coinciden en el verso $9 \mathrm{ni}$ con el manuscrito ni con la príncipe. Dice: purificó el cuchillo los perfectos ! modos que religión zelante ordena. Las variaciones de los versos 2 y 10 no tienen más interés que el de serlo: en el 2 el $s u$ me parece más expresivo; en el 10, sea modos o medios (mejor esto último), es evidente que es plural y que concuerda con su adjetivo perfectos. Dejaríamos, pues, la versión de la edición de 1629 con $s u$ y medios, corrigiendo la errata de ese singular. Las otras dos, sí que presentan interés.

Fortuna más crecida añade a la idea de alta fortuna un recuerdo de la luna. Rimar fortuna con el astro nocturno es frecuente en la poesía, porque es un tópico (o Fortuna / velut luna, en los Carmina Burana) relacionar la crecida y mengua, alternativas, de la luna con los avatares de la suerte. E1 mismo Conde nos pone ejemplos:

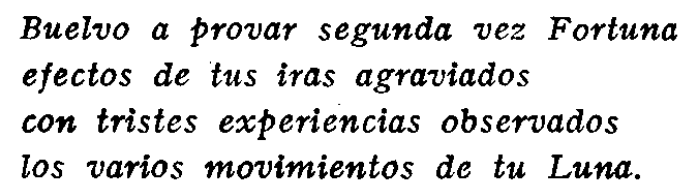

28 Cancionero del Marqués de Siete Iglesias (en El Criticón..., Badajoz, 1935, número 2, págs. 5-23). (Recogido en sus Curiosidades bibliográficas..., Madrid, 1946, páginas 17-33.)

29 En la Agudeza. V. más adelante. 
que el ancora acogió de mi fortuna;

Norte es sin observancias de la Luna 30.

Por esta razón, y porque evitamos la cacofonía con su vida (que, además, es la rima siguiente), como lector prefiero la versión del manuscrito, como ya alguien en la época la prefirió; pero, desde el impreso que he citado antes, editado tan sólo un año después de escribirse el poema, hasta las seis ediciones de Obras y la totalidad de los manuscritos que recuerdo, ponen subida, versión que - sin olvidarse en absoluto de la variantehay que aceptar en rigor de editor.

Una de las variantes del verso 9 nos lleva a un problema de fuentes. Teníamos: Que allí fio a, calificó, purificó un cuchillo. A la misma ocasión escribió Góngora el soneto Ser pudiera tu pira levantada $(365$ de Millé). El verso 9, precisamente, dice: Purifico el cuchillo, en vez de llama ${ }^{31}$, a lo cual hay que añadir la rima en -ida (como el de Villamediana), esclarecida y vida.

En este aspecto, la versión de 1629 me parece en lo poético la peor y en lo lógico la más torpe. No fio al cuchillo (bien conocidos, hasta la saciedad, son los preparativos sacramentales de don Rodrigo) los medios perfectos que la religión ordena, sino que purificó este cuchillo los medios ya empleados. (El calificó es peor, aunque puede pasar como un intensivo: el cuchillo califica, la muerte perfecta califica esos medios). I a identidad de palabras con Góngora nos deja insoluble el problema :

a) Villamediana escribió purificó, y no otra cosa, por imitar a Góngora, al que infinitas veces (como ya hemos señalado en este trabajo) sigue. Esto es lo más probable, pero:

b) Un copista cualquiera, al leer calificó, por ejemplo, recordó lo que había dicho Góngora e hizo el mismo razonamiento que yo acabo de hacer, o bien, si no era puntilloso, siguió a Góngora porque mejoraba el soneto por su cuenta. O bien :

c) Es variante del propio Villamediana.

30 Obras, 1629 , págs. 87 y 78, respectivamente. V. también el siguiente cuarteto de un soneto titulado Definición de la mujer: Es la mujer un mar todo fortuna, I una mudable vela a todo viento, / es cometa de fácil movimiento, / sol en el rostro, y en el alma luna (Obras, 1643, pág. 436). V. la nota 39.

31 Señaló ya esta fuente, o esta coincidencia - ya que ambos fueron escritos en los mismos días-, Salcedo Coronel, ob. cit., pág. 770. 
1630.- Los cuatro textos que quedan son posteriores a la muerte del autor y posteriores a la primera edición. Los veremos con mucho menos detenimiento. Un año después de publicadas sus Obras, Pellicer se empeñó, consiguiéndolo, en llenar un libro con noticias del ave Fénix ${ }^{32}$, a base de la fatigosa, si enorme, erudición que Dios le dio. Entre otras cosas de las que tuvo que echar mano para salir airoso, eligió la fábula del Conde al pájaro de Arabia. La editó con estas palabras :

"En español escriuió el poema del Fénix don Juan de Tassis, Conde de Villamediana, cuyo eleuado ingenio corre parejos con los de la antiguedad; y por parecerme que hago lisonja a los curiosos, por la falta que ay de sus obras, le estamparé aquí entero."

Pellicer hizo un gran servicio a nuestro poeta, pues este poema -además de ser muy oscuro- es el peor parado en manos de los editores de sus ediciones. El texto de Pellicer es infinitamente más depurado y viene además avalado por dos circunstancias: 1." Como él da a entender en el párrafo citado, antes de que se editasen las obras del Conde (cuya fecha más antigua de preliminares es octubre de 1628), ya había él terminado su libro, que tiene la censura (de Quevedo) datada en febrero de $1628 \mathrm{y}$, un mes más tarde, el Privilegio. Teniendo en cuenta que es una obra erudita, debemos suponer que tardo algún tiempo. Con lo cual vemos que, en cuanto a cronología, tiene igual o mayor autoridad que la primera edición. 2." Un tal Arcos, que firma en la nortada y pone fecha (1633), corrigio con gran cuidado todo el ejemplar de Obras del Conde de la edición príncipe que manejo ${ }^{\text {ss }}$ Es una corrección detallada y sistemática, donde se añaden hasta estrofas enteras (en el Faetb́n), se interpolan versos, se tachan otros $y$ se anotan a veces hasta coincidencias con G6ngora. Evidentemente disponía de un manuscrito de casi todas las composiciones, mejor que el utilizado por el editor, $y$, sobre todo, entendía mejor que él la poesía del Conde. Pues bien, todas las variantes del texto de Pellicer están señaladas por Arcos. Fiste tiene algunas más, pero cabe dudar si son correcciones de erratas, ya que no son fundamentales. En general, salvo pequeñas excepciones, podemos asegurar que $\mathrm{Pe}$ llicer y Arcos leían un texto idéntico. Como ya he dicho que este último

32 El Fénix y su historia natural... Madrid, Imprenta del Reino, 1630. B. N. R-18.331. El poema del Conde se copia del folio 187 r. al $198 \mathrm{v}$.

s3 Biblioteca del Instituto aMiguel de Cervantes», del C. S. I. C., sig. XV/41. 
tenía un manuscrito con casi todas las correcciones, no hay por qué pensar que siguió la edición de Pellicer, sino que ambos tienen un manuscrito muy parecido, es decir, muy próximo al de Villamediana, o bien que, a pesar de tenerlo, este Arcos, buen conocedor de lo que hacía, deja su manuscrito y elige el texto de Pellicer (retocándolo cuando lo cree conveniente), por ser el mejor. De cualquier manera, esta coincidencia avala los textos, que desde luego son completamente legibles, y no así el de 1629, al que los correctores añaden versos enteros. Este artículo está saliendo ya excesivamente largo y monótono para que señale ahora las variantes, cerca de un centenar, que tengo recogidas. He querido, tan sólo, demostrar la autoridad de este texto disperso en contra de la impureza de la primera edición, en el caso de La Fénix. El casi centenar de variantes dice ya bastante. Precisaré, sin embargo, que en unas pocas ocasiones la lectura de las Obras convence más que la de Pellicer.

\section{8}

1635.-Giovan Battista Manso publicó el soneto, ya incluido en las Obras, De engañosas quimeras alimento, en su Nomiche ${ }^{34}$, con tal cantidad de variantes que lo hacen una versión distinta. Esto ha llamado ya la atención de los eruditos: de Croce ${ }^{35}$, que lo copia de un manuscrito procedente de la Academia degli Oziosi; de Fucilla ${ }^{36}$, que lo toma del Nomiche, y de Prieto ${ }^{37}$. El soneto, en las versiones conservadas en Italia (la del Nomiche y la del manuscrito de los Ociosos, ambas entre sí idénticas), va dirigido a Manso, cuyo nombre se incluye en el verso 13. En los trabajos citados de Croce y Fucilla encontrará el lector los textos.

1642 y 1648.-A Gracián, como es lógico, le gustaban mucho los versos de nuestro poeta, que está muy bien representado en la Agudeza ${ }^{38}$, por medio de varias composiciones, copiadas casi siempre en compañía de

34 Venecia, 1635, pág. 291.

35 Loc. cit., pág. 190.

s6 Giovan Rattista Marino y el Conde de Villamediana (en Relaciones hispanoitalianas, Madrid, C. S. I. C., 1953, pág. 161).

37 Maestros italianos, I, Barcelora, Planeta, 1962, págs. 405-407.

38 Primera edición : Madrid, Juan Sínchez, 1642. B. N. R-15.000; segunda edición : Huesca, Juan Nogués, 1648. 
elogios rotundos. En la primera edición se ocupa de Villamediana en los siguientes lugares:

Fol. 14 r. y v. : "Entre la vida y la muerte de vn mostruo de fortuna, otro que lo fue en todo, cantó esta disonancia.) $\mathrm{Y}$ copia entero Este que en la fortuna más subida, con las variantes que ya he señalado.

Fols. 29 v. y 30 r. : "Grandemente dixo el Conde de Villamediana." Copia el primer cuarteto del soneto Es la mujer un mar todo fortuna. No aparece en las ediciones de Zaragoza, pero sí en las de Madrid, desde la primera ${ }^{39}$. Estos cuatro versos no ofrecen variantes.

Fol. 34 r. y v.: "... en este perfectíssimo soneto, que fue trofeo de la poesia española, contrapuso vn Príncipe de España, y más en la agudeza, lo turbio del corazón humano con la claridad de vna fuente.) Copia el soneto Risa del monte, de las aves liras, que se ha atribuido al Conde en varios lugares y cuya paternidad es una de las más problemáticas que conozco.

Se ha atribuido con insistencia a Villamediana y a Saavedra Fajardo. Esste lo incluyó, sin decir que fuese suyo, pero también sin negarlo, en su República Literaria (desde la primera edición: Cabrera: Juicio de Artes y Sciencias, 1655). Lorenzo Ortiz, poco después, en Ver, oir, oler, gustar y tocar (León de Francia, 1678), lo vuelve a publicar como del autor de las Empresas. Y, siguiendo esta tradición, García de Diego lo cree de Saavedra en su edición de la República Literaria, en Clásicos Castellanos (Madrid, 1922). Ninguno de los editores de la obra de Saavedra han dado razones críticas para fundamentar esta atribución. Y por este camino el problema sigue como en el año 1655 : ¿ Es un ejemplo propio o ajeno de Saavedra Fajardo?

De no haber surgido nuevas atribuciones, con la grave duda de que el gran prosista político fuese capaz de escribirlo, se hubiese dejado como suyo. Pero la crítica ha tenido siempre sus dudas, y ya Böhl de Faber, en su Floresta, lo editó como anónimo. $\mathrm{Y}$ es que hay impresos y manuscritos desde muy temprano que contradicen la atribución a Saavedra Fajardo.

Antes de que apareciese el Juicio de Artes y Sciencias, trece años antes, un hombre que tiene motivos para ser considerado como autoridad en

s9 V. la nota 30. Aparece anónimo en manuscritos, como en el 17.719 de la B. N. 
la poesía barroca, Gracián, lo publicó en la edición príncipe de la $A g u$ deza, considerándolo de "un príncipe en sangre y más en el ingenio". Esta calificación cuadra bien a Villamediana ${ }^{40}$. Essto abre otra tradición que da como del Conde el poema. De él lo juzgó Mayans en su Retórica, en el siglo xvirI (Valencia, 1757, tomo II, pág. 217). Y lo mismo hace Castro en el XIx, en el tomo XLII de Rivadeneyra (Madrid, 1857, página 157). Es él quien hizo primero la bibliografía del soneto, partiendo de Gracián.

Pero la verdadera historia se remonta a veintiún años antes, treinta y cuatro, por tanto, antes de ser atribuido a Saavedra. El primero en editarlo fue Tirso de Molina en sus Cigarrales de Toledo (Madrid, 1621), que lo titula $A$ una fuente y lo atribuye a (un príncipe de Castilla, igual en el imperio y en la sangre, siendo ésta de la mejor de Europan ${ }^{41}$. Bien claro está de dónde lo toma Gracián y de dónde sacó la atribución, de forma que raya en el plagio, hasta tal punto que sería interesante comprobar lo que la Agudeza debe a libros de miscelánea, semejante a los Cigarrales de Tirso. De aquí viene la sospecha de que sea de Villamediana, aunque no se ha publicado en sus Obras.

Ninguna de estas dos atribuciones me convencen. El texto de Tirso es muy terminante y muy temprano, lo que hace que debamos creer la atribución a un noble que fuese ingenioso poeta. Essto desecha la atribución a Saavedra. Pero no nos lleva a asegurar que sea de Villamediana, porque hay varios nobles que escriben buenos versos en 1621, siendo los mejores con Tassis, Salinas y Esquilache. Si el estilo cuenta algo en estas cuestiones, nadie dudará en atribuirlo al último. El blandísimo tono, el sentido de la naturaleza, el rococó diminutivo guijuelas, el afectado me enamora y el moralizante terceto final, amanerado y sin desengaño verdadero, cuadran perfectamente con don Francisco de Borja, que fue 1lamado por Gracián "Príncipe de Esquilache y príncipe de la poesía", fórmula semjante a la empleada en la atribución al soneto en cuestión. Como lector, yo apostaría que no es de Salinas y con más conocimiento que no es de Villamediana.

40 Príncipe lo llama Manuel Ponce en la epístola que le dirigió en defensa de su Faetón, ms. $18.722^{34}$ de la B. N. (editada por Quilis y Rozas en Revista de Filología, 1961, XLIV, págs. 411-423).

41 Cito por la edición de SaID Armesto. Madrid, Renacimiento, 1913, págs. 326 . 327. No hay motivos para que Tirso ocultase su paternidad, y sus palabras lo indican ajeno tajantemente. A Tirso lo atribuye, con interrogaciones, A. DEL HoYo en Antología del soneto clásico español (Madrid, Aguilar, 1963, pág. 122). 
En favor de esta atribución a Esquilache hay, por lo menos, un dato documental que no deja en el aire totalmente mi parecer: en el manuscrito 4.141 de la Biblioteca Nacional, de Madrid, en la página 291 se le atribuye. $\mathrm{Y}$, sin embargo, ¿cómo el príncipe, que tan buen cuidado tuvo de editar sus obras, no lo recogió ? Es difícil creer que no le gustase.

Salga aún más problemática de mis manos esta atribución : ¿'Tirso, Saavedra, Villamediana o Esquilache?

En la segunda edición de la Agudeza, al ampliar mucho su obra, añadió nuevos ejemplos y noticias de Villamediana. En la página 80 copia estas dos redondillas, que no parece que se hubieran editado hasta el momento ${ }^{42}$ :

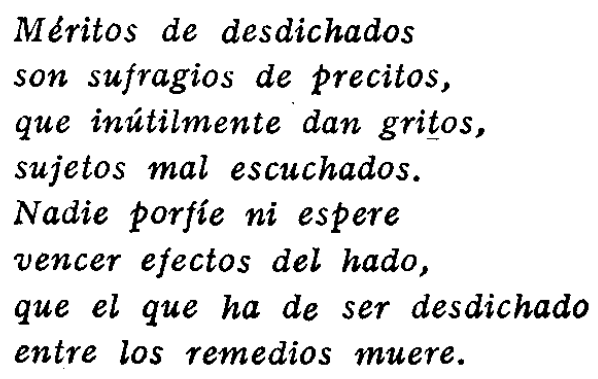

En la página 110 dice: "Iuntó lo sentencioso con lo crítico el de Villamediana, que fue el único en nuestros tiempos en lo picanten, y copia el soneto Si para mal contentos hay sagrado, sin variantes con respecto a la primera edición. En la página 169 copia sin variantes los cuatro últimos versos de la fábula de Dafne y Apolo en verso corto que las Obras atribuyen al Conde ${ }^{43}$. En la página 170 ejemplifica un caso en que "el Conde de Villamediana dio primero la razón que la propuestan con esta redondilla :

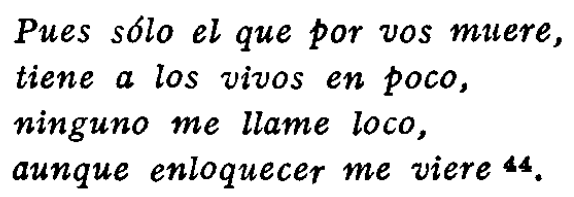

42 La composición a que pertenecen la editó por vez primera Rosales en su Antología del Conde (Madrid, Nacional, 1944, pág. 292). En esta edición las dos redondillas están separadas por otras cinco.

43 No creo que sea de éi, sino de Collado del Hierro, como estudié en mi tesis doctoral, leída en la Facultad de Madrid, y hoy en prensa : La poesía del Conde de Villamediana.

4 Obras, 1629, pág. 372. 
En la página 231 refiere, sin decir el nombre del protagonista, el suceso de los amores reales: "Lo mismo es quando es la equivocación atrevida y peligrosa; como aquel que en unas fiestas sacó la librea sembrada de reales de a ocho, con esta letra: Son mis amores reales.)

Por fin, en la página 291 copia el bello soneto No entre Scila y Caribdis viva nave, que ya estaba editado en las Obras, desde la primera edición (pág. 67). No contiene variantes.

1662. - El último texto disperso tiene poca importancia. Se trata de una redondilla suelta del Conde que se glosó como asunto obligado en la Academia que se celebró en 23 de abril en casa Cé don Melchor de Almeida, en Madrid ${ }^{45}$. Los cuatro versos, que no se han conservado en otros impresos, ni en manuscritos conocidos por mí, fueron glosados por don Diego de Sotomayor, Caballero del Hábito de Santiago, en unas décimas que empiezan Abrasada voluntad. Son éstos:

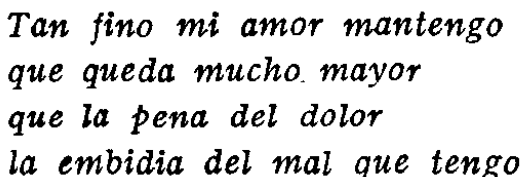

juan Manuel Rozas

45 Madrid, s. i., 1662, fol. 17 v. B. N. R-5.198. 